\title{
Resistência de Genótipos de Algodoeiro a Anthonomus grandis Boh., Frankliniella sp. e Aphis gossypii Glover
}

\author{
Lauro Morales ${ }^{1}$, Pedro Cena ${ }^{2}$, Fernando P. Mendes Neto ${ }^{2}$, \\ Servilio F. Costa ${ }^{2}$ e Fernando T. de Oliveira ${ }^{1}$ \\ ${ }^{1}$ EMATER-Paraná,Av. Inglaterra 910,86046-430, Londrina, PR. \\ ${ }^{2}$ EMATER-Paraná.Av. Amazonas 463,87360-000, Goioerê, PR. \\ An. Soc. Entomol. Brasil 26(1): 93-97 (1997) \\ Resistance of Cotton Genotypes to Anthonomus grandis Boh., \\ Frankliniella sp. and Aphis gossypii Glover
}

\begin{abstract}
Resistance to boll weevil Anthonomus grandis, Frankliniella sp. and Aphis gossypii on five genotypes of cotton (Gossypium hirsutum) was evaluated. Four evaluations for boll weevil were conducted observing punctured buds. Resistance to thrips and greenbug was evaluated 32 days after emergence, observing dead or damaged plants. First evaluation showed $4.6 \%$ attacked buds in Sicot 3 and $48.1 \%$ in IAC-20; 130 days after emergence, buds of all genotypes were equally damaged. Oklahoma Red showed only $3.0 \%$ of dead or damaged plants due to thrips and greenbug attack, while IAC-20 presented $21.0 \%$ of damaged plants.
\end{abstract}

KEY WORDS: Insecta, non-preference, boll weevil, thrips, greenbug.

RESUMO- Avaliou-se a resistência ao bicudo Anthonomus grandis Boh. ao tripes Frankliniella sp. e ao pulgão do algodoeiro Aphis gossypii Glover, dos genótipos do algodoeiro (Gossypium hirsutum) Sicot 3, Oklahoma Red, Siocra, Paraná 3 e da cultivar IAC-20 (testemunha). Para o bicudo foram feitas quatro avaliações, observando-se, diretamente nas plantas, botões com puncturas de alimentação e/ou oviposição. Para tripes e pulgões foram avaliadas, 32 dias após a emergência, plantas mortas e/ou comprometidas pelo ataque. Na primeira avaliação, Sicot 3 apresentou 4,6 \% de botões atacados, enquanto a IAC-20 apresentou 48,1\%; 130 dias após a emergência, o número de botões atacados foi semelhante em todos os genótipos. Oklahoma Red apresentou o menor número $(3,0 \%)$ de plantas comprometidas e/ou mortas pelo ataque de tripes e pulgões, enquanto IAC-20 apresentou $21,0 \%$.

PALAVRAS-CHAVE: Insecta, não preferência, bicudo, tripes, pulgão.

A introdução do bicudo, Anthonomus grandis Boh. (Coleoptera:Curculionidae), no complexo de pragas do algodoeiro (Gossypium hirsutum) no Estado do Paraná, provocou a elevação do custo de produção devido ao aumento, nos últimos cinco anos, do número de aplicações de inseticidas, que passou de 5,4 para 10,1 em média (L. Morales, não publicado). Além disso, são freqüentes as aplicações de inseticidas de largo espectro para 
o controle de pulgões e tripes, no início do desenvolvimento da cultura, comprometendo o estabelecimento de inimigos naturais. Nos últimos anos, têm sido reconhecidas as limitações do controle de pragas através da utilização exclusiva dos inseticidas, o que tem sugerido a busca por características de resistência aos insetos e sua incorporação às cultivares comerciais (Thomson \& Lee 1980). Dentre as características que conferem algum tipo de resistência às pragas do algodoeiro, Jones et al. (1986) citam, entre outras, a bráctea frego e as plantas avermelhadas. Embora seja reconhecida como uma tática importante nos programas de manejo integrado de pragas (MIP) (Vendramim 1984, Lara 1991), poucos trabalhos têm sido apresentados no Brasil com referência a plantas resistentes. O objetivo do trabalho foi avaliar a resistência de genótipos de algodoeiro da coleção da OCEPARPesquisa (COODETEC), com característica de bráctea frego, plantas avermelhadas e folha okra, ao bicudo A. grandis, tripes Frankliniella sp. e pulgão Aphis gossypii Glover.

\section{Material e Métodos}

O experimento foi conduzido durante a safra 1994/95 em IV Centenário-PR, na propriedade Sementes Chapadão utilizando-se os genótipos de algodoeiro Sicot 3 (bráctea frego), Oklahoma Red (plantas avermelhadas) e Siocra (folha okra), obtidos da coleção da OCEPAR-Pesquisa, Cascavel, PR e as cultivares Paraná 3 e IAC-20 (testemunha suscetível). As sementes foram tratadas com fungicidas e o plantio efetuado manualmente, distribuindo-se 30 sementes $/ \mathrm{m}$ linear. Utilizou-se um delineamento experimental de blocos ao acaso com quatro repetições, sendo cada parcela constituída de cinco linhas de $8 \mathrm{~m}$ de comprimento e espaçadas de $90 \mathrm{~cm}$. A semeadura foi realizada em 01/12/1994 e o desbaste 40 dias após a germinação mantendo-se 7-8 plantas/m linear. Os ensaios foram implantados tardiamente objetivando a ocorrência de altas populações do bicudo-do-algodoeiro.
As avaliações de ataque do bicudo foram feitas observando-se, diretamente nas plantas 60 botões/parcela com puncturas de alimentacão e/ou oviposição aos 107,115,122, e 130 dias após a emergência. Aos 120 dias após a germinação foram coletados no solo 120 botoes de cada material, mantidos em saco de papel à temperatura ambiente até a emergência dos adultos, sendo poste- riormente pesados individualmente. Os resultados foram submetidos à análise de variância e as médias comparadas pelo teste de Duncan $(\mathrm{P}<0,05)$.

Aos 32 dias após a germinação, as plantas foram avaliadas verificando-se o comprometimento provocado por tripes e pulgões, sendo, então, efetuado o controle através de duas aplicações (35 e 42 dias) do inseticida monocrotophos na dosagem de 0,50 1/ha. Para esta avaliação foram observadas as plantas em 3 $\mathrm{m}$ lineares, das três linhas internas, anotandose aquelas comprometidas e/ou mortas (com a gema apical danificada e/ou morta) pelo ataque dos insetos.

\section{Resultados e Discussão}

Na primeira avaliação o número de botões atacados por $A$. grandis foi de apenas 4,6\% em Sicot 3 e de 48,1\% em IAC-20 (testemunha suscetível) (ca. de 10 vezes maior). Soares \& Lara (1993) relataram que o genótipo La 780843FR, portador do caráter frego, foi cerca de duas vezes menos atacado do que o IAC-20. Hunter et al. (1985)verificaram que a bráctea frego inibiu a alimentação e a oviposição do bicudo, mesmo em altas populações. Além da não preferência, Parrot et al. (1973) observaram que a mortalidade do bicudo por inseticidas foi maior na variedade frego, favorecendo a eficiência dos produtos testados. Oklahoma Red, Paraná 3 e Siocra apresentaram índices de 17,9; 43,9 e 63,0\% respectivamente (Tabela 1). Nas demais avaliações os resultados foram semelhantes, exceto na última, quando todos os materiais apresentaram incidência igual de botões florais atacados. Os 


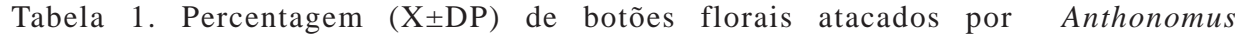
grandis em cinco genótipos de algodoeiro, em quatro datas de amostragem.

\begin{tabular}{lcccccr}
\hline & \multicolumn{7}{c}{ Data } \\
\cline { 2 - 7 } Genótipo & $23 / 03$ & $30 / 03$ & $07 / 04$ & $14 / 04$ & Média \\
\hline \multirow{2}{*}{ Sicot 3 } & $4,6 \pm 3,9 \mathrm{a}^{1}$ & $4,2 \pm 2,8$ a & $11,2 \pm 2,1$ a & $13,6 \pm 12,8$ a & $8,4 \pm 4,7$ \\
Oklahoma Red & $17,9 \pm 12,4$ b & $15,6 \pm 7,6$ b & $18,3 \pm 3,6$ a & $15,9 \pm 9,4$ a & $16,9 \pm 1,4$ \\
Siocra & $63,3 \pm 9,8$ c & $18,0 \pm 5,2$ bc & $40,5 \pm 10,1$ b & $17,5 \pm 8,3$ a & $34,8 \pm 21,8$ \\
Paraná 3 & $43,9 \pm 20,3$ c & $24,7 \pm 5,6$ bc & $50,5 \pm 10,1 \mathrm{~b}$ & $16,0 \pm 13,4$ a & $33,8 \pm 16,1$ \\
IAC-20 & $48,1 \pm 7,3$ c & $29,1 \pm 9,1$ c & $53,7 \pm 11,9$ b & $16,3 \pm 10,6$ a & $36,8 \pm 17,2$ \\
\hline
\end{tabular}

'Médias seguidas de mesma letra, na mesma coluna, não diferem estatisticamente pelo teste de Duncan, ao nível de $5 \%$ de probabilidade.

resultados demonstraram que bráctea frego e plantas avermelhadas são características que, se incorporadas às variedades comerciais, podem contribuir para a convivência com o bicudo-do-algodoeiro, com menor utilização de inseticidas. Os dados do trabalho demonstraram, ainda, que o número de insetos emergidos dos botões florais foi diferente entre os genótipos testados verificando-se a maior emergência $(56,5 \%)$ na cultivar Paraná 3 e a menor $(12,8 \%)$ no Siocra (Tabela 2). Essa diferença pode estar correlacionada com o tamanho dos botões florais observados nos diferentes materiais, causando maior ou menor mortalida- de por dessecação. O peso médio dos adultos emergidos destas estruturas não diferiu entre os materiais testados, sugerindo que a não preferência seja por oviposição (Tabela 2). F. M. Lara, J. J. Soares \& J.C. Barbosa (não publicado) relataram a não preferência para oviposição do bicudo do algodoeiro em genótipos com a característica de bráctea frego, en-tretanto, não foram detectadas diferenças significativas, quanto à preferência para alimentação.

Devido à ocorrência simultânea de tripes e pulgões durante o ensaio, e à natureza dos danos provocados, não foi possível avaliar o

Tabela 2. Peso e emergência $(\mathrm{X} \pm \mathrm{DP})$ de adultos de Anthonomus grandis oriundos de botões florais, coletados no solo, em cinco genótipos de algodoeiro.

\begin{tabular}{lcl}
\hline Genótipo & Insetos emergidos $(\%)$ & Peso $(\mathrm{g})$ \\
\hline Siocra & $12,8 \pm 12,7 \mathrm{a}^{1}$ & $2,65 \pm 0,31 \mathrm{a}$ \\
Sicot 3 & $29,7 \pm 15,9 \mathrm{~b}$ & $3,09 \pm 0,34 \mathrm{a}$ \\
Oklahoma Red & $33,9 \pm 7,4 \mathrm{bc}$ & $2,91 \pm 0,37 \mathrm{a}$ \\
IAC- 20 & $38,5 \pm 11,3 \mathrm{bc}$ & $2,94 \pm 0,21 \mathrm{a}$ \\
Paraná 3 & $56,5 \pm 2,7 \mathrm{c}$ & $2,66 \pm 0,31 \mathrm{a}$ \\
\hline
\end{tabular}

'Médias seguidas de mesma letra não diferem estatisticamente pelo teste de Duncan, ao nível de $5 \%$ de probabilidade. 


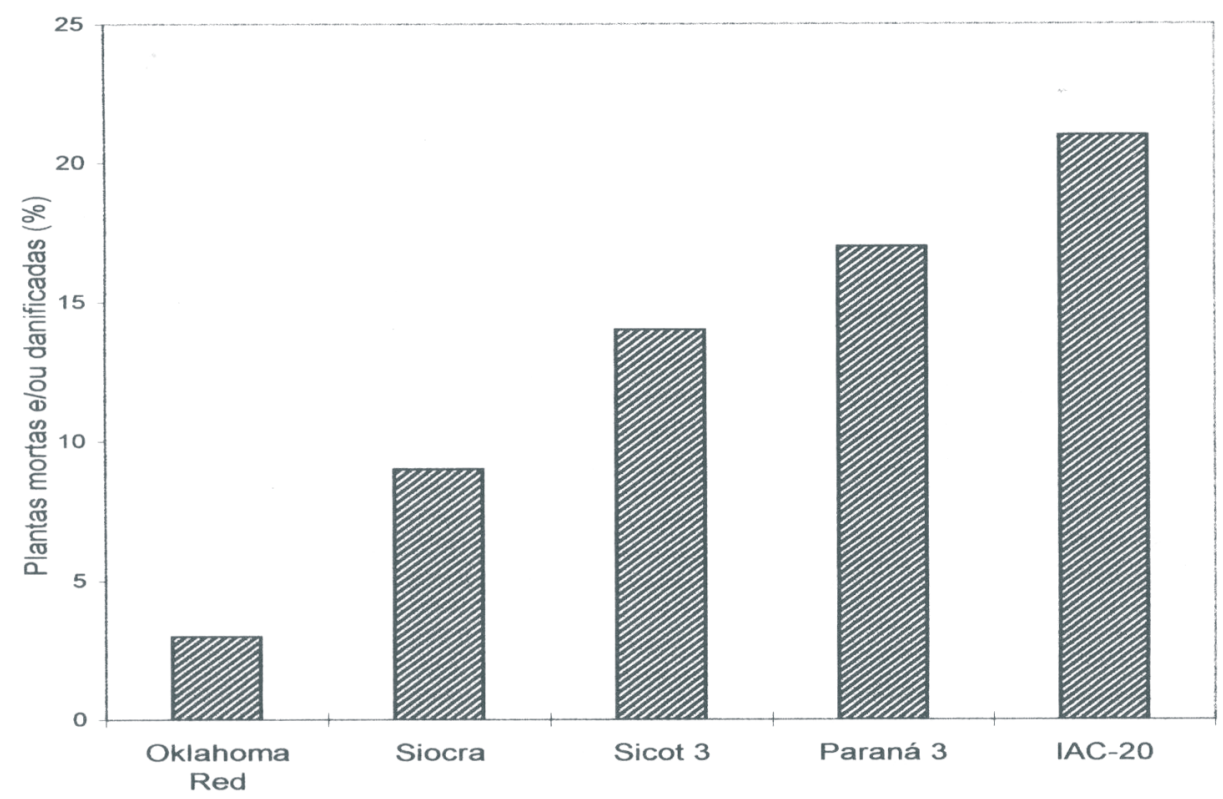

Figura 1. Percentagem de plantas mortas e/ou danificadas de cinco genótipos de algodoeiro devido ao ataque de pulgões e tripes.

prejuízo causada pelas pragas separadamente. O número de plantas danificadas e/ou mortas por estes insetos foi $7 \mathrm{x}$ menor no genótipo Oklahoma Red (3,0 \%) quando comparada com o IAC-20, que foi o material que apresentou maior dano (21,0\%) (Fig. 1), sugerindo que essa característica de plantas avermelhadas pode conferir resistência a estes dois insetos ou a um deles particularmente. Embora não sejam consideradas, em algumas regiões produtoras, pragas-chaves na cultura do algodoeiro (Tynes et al. 1978, Bohmfalk et al. 1982), o aparecimento de altas populações de tripes e pulgões no início do crescimento da cultura pode causar atraso no desenvolvimento das plantas (Bohmfalk et al. 1982, Santos 1993) e até a morte (Bohmfalk et al. 1982). Vendramim \& Nakano (1981) constataram redução na altura das plantas e no peso de algodão em caroço, quando atacadas por pulgões.

Em conclusão, os resultados demonstraram que os genótipos testados constituemse em fontes de resistência aos insetos avalia- dos, sugerindo que o incremento de investigações, incorporarando estas características às variedades comerciais, possibilitaria a convivência com as pragas do algodoeiro, com menor uso de inseticidas.

\section{Agradecimentos}

Ao Sr. Damaceno M. Braga pela cessão da área para realização do experimento. Ao Dr. Delano M. Gondin da OCEPAR- Pesquisa. (COODETEC), pela fornecimento e tratamento das sementes. Ao Prof. Dr. Fernando M. Lara (UNESP-Jaboticabal), ao Dr. Flávio Moscardi (Embrapa-Soja-Londrina) e a dois revisores anónimos pelas sugestões.

\section{Literatura Citada}

Bohmfalk, G. T., R. E. Frisbie, R. B. M Sterling \& A. E. Knutson, 1982. Identi ficacion, biology and sampling of cotton insects. Texas Agric. Ext. Serv, 43p. 
Hunter,C. R., T. F. Leigh, C. Lincoln, B. A. Waddie \& L. Bariola, 1985. Evaluation of selected cross section of cotton for resistance to boll weevil. Arkansas Agric. Exp. Stn.Bull,700p.

Jones,J.E.,J.B.Weaver \& M.F.Shuster, 1986. Plantas resistentes ao bicudo, p. 221- 249. In S. Barbosa, M. J. Lukefahr \& R. Braga Sobrinho (eds), O bicudo do algodoeiro. Brasília, Documento 4, EMBRAPA.-DDT.314p.

Lara, F. M. 1991. Princípios de resistência de plantas a insetos. São Paulo, ícone, 336p.

Parrot,W. L., J. N.Jenkins \&D.B. Smith, 1973. Frego bract cotton and normal bract cotton: How morphology affects control of boll weevils by insecticides. J.Econ. Entomol. 66:222-225.

Santos, W. J. 1993. Pragas do agodoeiro. p. 37-63. In Recomendações para a cultura do algodoeiro no Paraná. Inf. Pesq. 107, Londrina, IAPAR, 7 Ip.

Soares, J. J. \& F. M. Lara, 1993. Resistência do algodoeiro herbáceo a Anthonomus grandis Boheman, 1843 (Coleoptera: Curculionidae) e interações com inseticida. Pesq. Agropec. Bras. 28:1129-1135.

Thomson, N. J. \& J. A. Lee, 1980. Insect resistance in cotton: a review and prospectus for Australia. J. Aust. Inst. Agric. Sci. p. 75-86.

Tynes, J.S.,D.F.Clower\& D.Glover, 1978. Insect scouting and mana gement in cotton. LSU Coop. Ext. Serv., 32p.

Vendramim, J. D. 1984. A resistência de plantas e o manejo de pragas, p. 117-146. In W. B. Crocomo (ed.), Manejo integrado de pragas. Botucatu, UNESP, 358p.

Vendramim, J. D. \& O. Nakano, 1981. Avaliação de danos de Aphis gossypii Glover, 1877 (Homoptera:Aphididae) no algodoeiro cultivar IAC-17. An. Soe. Entomol. Brasil 1:89-96.

Recebido em 14/12/95. Aceito em 12/02/96. 